\title{
Benefícios para as Pequenas e Médias Empresas com as Mudanças nas Normas Brasileiras de Contabilidade
}

\author{
Benefits for the Small and Medium-Sized Enterprises Brought by the \\ Changes Made in the Brazilian Accounting Norms
}

\author{
Stephane Louise Boca Santa \\ stephanelou.bs@gmail.com \\ UFSC
}

\author{
Marcos Laffin \\ marcoslaffin@gmail.com \\ UFSC
}

\begin{abstract}
Resumo
Devido à relevância na economia e geração de empregos de pequenas e médias empresas, há necessidade de uma constante atualização no ramo dos negócios a fim de aperfeiçoar os processos de gestão e decisão. Com o objetivo de caracterizar a importância da contabilidade para as pequenas e médias empresas e evidenciar as contribuições da NBC TG 1000 para a gerência dessas empresas em relação à NBC T 19.13 realizou-se uma pesquisa bibliográfica com abordagem qualitativa, destacando as normas e a importância da informação contábil. Com o intuito de verificar as atualizações das normas, foi realizado um estudo comparativo das normas em questão, que possibilitou evidenciar as contribuições da NBC TG 1000 para estas empresas, em função das exigências de um número maior de informações decorrentes do registro e que ampliam os subsídios para a tomada de decisão.
\end{abstract}

Palavras-chave: Pequenas e médias empresas. Normas Brasileiras de Contabilidade. Informação contábil.

\begin{abstract}
Due to the importance for the economy and employment of the small and medium-sized companies, there is the need of an endless updating in business in order to improve actions concerned with management and decision making. In order to characterize the importance of accounting for the small and medium-sized companies, and to evince the contribution brought by NBC TG 1000 to the management of such enterprises in relation to NBC T 19.13, a bibliographical research with a qualitative approach was undertaken in which the accounting norms and the importance of accounting information are emphasized. With the aim of verifying the updating of the norms, a comparative study of the norms mentioned was undertaken which made evident the contributions of NBC TG 1000 for the above mentioned companies mainly because the latter norm demands a bigger amount of information in the accounting registrations which amplifies the data for decision making.
\end{abstract}

Keywords: Small and medium business. Brazilian Accounting Standards. Accounting information.

Artigo recebido em: 26.02.2012; Aceito em: 30.03.2012 


\section{INTRODUÇÃO}

As Pequenas e Médias empresas têm grande relevância para a economia no Brasil. Segundo Luciano Coutinho, presidente do Banco Nacional do Desenvolvimento (BNDES), as micro e pequenas empresas (MPEs) representam 98\% dos estabelecimentos formais na economia Brasileira. Em 2008 responderam por 13 milhões, em percentual 52,3\%, do total de empregados formais. Em 2010, foi a maior parte representativa de empregos formais. Vêm crescendo também o número de MPEs exportadoras. Entre 1998 e 2008 o número cresceu de 8.900 exportadoras para 12.917. (COUTINHO, 2011)

Essa efetiva participação no mercado de bens e serviços requer dos dirigentes, empreendedores, gestores e contadores envolvidos na entidade, uma constante atualização no ramo dos negócios, políticas econômicas e alterações que ocorrem tanto na legislação fiscal e societária, quanto nos procedimentos de gestão, visando garantir a sua continuidade em contextos de competitividade. Nas mudanças que ocorrem e que envolvem o controle patrimonial, é imprescindível a orientação e organização do processo contábil em seus aspectos de registro, controle, avaliação e perspectivas de empreendimento. Nesse sentido, uma contabilidade que resulte num sistema de informação possibilitará, além do gerenciamento das atividades, diversos elementos para análise econômica e financeira das empresas.

Com as recentes alterações na Lei 6.404/76 e a inserção de novos procedimentos na gestão das micro e pequenas empresas, o Conselho Federal de Contabilidade elaborou e publicou a Resolução CFC $\mathrm{n}^{\circ} 1.255$ que trata das Normas Brasileiras de Contabilidade, e aprovou a NBC T 19.41 - Contabilidade para Pequenas e Médias Empresas - a qual teve a sigla alterada para NBC TG 1000. Estas normas apresentam diversas alterações em relação à NBC T 19.13 Escrituração Contábil Simplificada para Microempresa e Empresa de Pequeno Porte e, sobretudo, a adequação às Normas Internacionais de Contabilidade.

Neste cenário, este estudo tem por objetivo geral caracterizar a importância da informação contábil para a gestão das Pequenas e Médias Empresas e evidenciar as contribuições da NBC TG 1000 para essas empresas, em relação à NBC T 19.13 - que tratava somente dos procedimentos simplificados -, visando responder a seguinte questão: quais foram os benefícios na gestão de pequenas e médias empresas com as mudanças nas Normas Brasileiras de Contabilidade?

Para responder, tem-se como objetivos específicos apresentar a importância da informação contábil para as Micro e Pequenas Empresas e traçar um paralelo entre a NBC T 19.13, de 2007 e a NBC T 19.41, de 2010, averiguando quais foram as alterações realizadas. A partir disso, identificar de que maneira as alterações contribuem para a gestão das pequenas e médias empresas.

\section{FUNDAMENTAÇÃO TEÓRICA}

Apresenta-se a atual situação da pequena e média empresa no Brasil, a sua importância para a economia e geração de emprego. Também será apresentado as características e diversos conceitos referente a estas empresas. A fim de contextualizar as Normas Brasileiras de Contabilidade, apresenta-se o histórico e evolução das normas.

\subsection{A Pequena e Média Empresa no Brasil}


As PMEs possuem importância relevante para a economia e estão prosperando. De acordo com a autora Bonfanti (2011, p.1) "hoje, 98\% de todas as companhias estabelecidas no país são de micro e pequeno porte", comprovando a importância destes empreendedores.

As microempresas despertam interesse em muitos empreendedores, pois são empreendimentos que surgem de forma modesta e muitas vezes familiar, e podem vir a tornar-se grandes organizações.

Segundo Souza (2011, p. 24):

a pequena empresa sempre esteve voltada para a geração de riqueza, atividade econômica, com ênfase na produção, consumo e acumulação de bens e serviços, despertando interesse e fascínio nos empreendedores, na humanidade. É com a criação de pequenas empresas que surgem grandes empresas.

No conjunto de suas atividades, estas empresas se destacam pelo potencial de se tornar competitivas e contribuírem na formação da economia do país. Entretanto, no mercado produtivo e de base capital excludente, é importante uma gestão qualificada do patrimônio, visando os ganhos de escala e sua continuidade.

As MPEs empresas requerem uma contabilidade dinâmica, que além do registro e do controle, possibilite ao microempresário tomar decisões e gerenciar a empresa conforme as instabilidades do mercado, para que elas possam superar os momentos de retenção da economia e progredir em momentos econômicos favoráveis, para contribuir com a geração de empregos e com o desenvolvimento do contexto em que se insere.

\subsection{Características das Pequenas e Médias Empresas}

As PMEs necessitarem de uma boa gestão, com informações relevantes e contabilidade conforme a NBC TG 1000.

Segundo o Instituto Brasileiro de Geografia e Estatística - IBGE (2003) são características das MPEs a baixa intensidade de capital; altas taxas de natalidade e mortalidade; a mão-de-obra ocupada por membros da família, sócios e inclusive o proprietário; o poder de decisão dessas empresas é centralizado; um estreito vínculo entre a pessoa física (proprietário) e a jurídica (empresa) principalmente em termos contábeis e financeiros, inclusive os registros contábeis pouco adequados; contratação direta de mão-de-obra, normalmente não qualificada ou semiqualificada; há pouco investimento em inovação tecnológica; dificuldades quanto ao financiamento do capital de giro; e relação de complementaridade e subordinação referente as empresas de grande porte.

Segundo Vilga, Farah e Giuliani (2010) o proprietário objetiva em sua empresa, suas aspiração pessoal, a pessoa jurídica é substituída pela física em diversas situações, traduzindo em uma identidade total. Quando a vida pessoal do proprietário está prosperando, a empresa é favorecida, caso contrário, fatores particulares do proprietário podem afetar negativamente a empresa.

Uma fragilidade empresarial é a dificuldade e quase inexistência da contabilidade financeira, com relatórios contábeis expondo a realidade das MPEs, bem como informações internas, para fins gerenciais. Constantemente há situações onde é necessário a tomada de decisão e as informações contábeis auxiliariam, pois permite demonstrar a realidade atual da empresa e fazer previsões do negócio. (SILVA, AMORIM E SILVA, 2011)

Muitos empreendedores tem capital para montar um negócio, mas desconhecem outros fatores que também são importantes e necessários para o sucesso do empreendimento, possuem o 
capital e resolvem montar um negócio desconhecendo todos os outros fatores, por exemplo, capital de giro, a relação que tem entre despesas e receitas, os custos para a continuidade do negócio, que são necessários ao sucesso do empreendimento. (HENRIQUE, 2008)

O Fórum Permanente das microempresas e empresas de pequeno porte (2007, p. 7) afirma que:

As microempresas e empresas de pequeno porte têm características específicas que as distinguem de organizações maiores. Conhecer e compreender tais características é fundamental para oferecer a elas o apoio adequado, a partir da formulação de políticas, programas e ações que efetivamente estejam direcionadas ao segmento.

Com o objetivo de estabelecer um perfil dessas empresas o Fórum Permanente das microempresas e empresas de pequeno porte, descreve algumas dessas características. Estas empresas possuem nível de organização reduzido, seja contábil, gerencial ou estrutural; as demandas destas empresas quase sempre surgem de uma ideia ou da necessidade pertinente a empresa; as ME e EPPs têm dificuldade em relação a demonstrativos contábeis ou técnicos de comprovar suas necessidades e aptidões; o capital é reduzido e há ausência de recursos humanos qualificados; a característica básica é a falta de estrutura, visão e ausência de conhecimento técnico, geralmente o empresário é o responsável por todas as áreas; não há o entendimento sobre a importância da inovação e a sua relação com a longevidade da empresa; o nível de faturamento é baixo; capacidade de geração de trabalho. (FÓRUM PERMANENTE DAS MICROEMPRESAS E EMPRESAS DE PEQUENO PORTE, 2007)

\subsection{Classificação da Pequena e Média Empresa}

A existência de pequenos empreendimentos vem de longa data e durante muito tempo seu modo de produção era realizado manualmente e em condições contingentes. Com referência aos aspectos administrativos, uma definição legal para este ramo de negócios surge nos Estados Unidos, em 1948. Segundo Souza (2011), foi realizado "uma espécie de estatuto da pequena empresa, esclarecendo quais seriam as premissas básicas para que uma entidade fosse considerada pequena". Foram três premissas, a primeira dizia que "para ser uma pequena empresa não poderia ter uma posição dominante no comércio ou na indústria". A segunda dizia que "não poderia fazer a contratação de mais de 500 funcionários" e por último dizia que "teria que ser possuída e operada de forma independente". (SOUZA, 2011, p.23). Este primeiro estatuto estabelecia relações de forças produtivas e acentuava a delimitação do tamanho da empresa, o que não impediu de ampliar o número de empresas dessa natureza.

Várias são as características da definição para pequenas empresas, variando conforme o assunto a ser tratado e da análise a ser realizada em cada definição e situação, podendo elas estarem sendo utilizadas a fim de caracterizar o número de funcionários, a receita bruta auferida, o volume de produção, o tipo de produto ou serviço que realiza.

A denominação microempresa foi utilizada pela legislação brasileira a partir da Lei $\mathrm{n}^{\circ} 7.256$ de 27 de novembro de 1984. Com esta lei, as microempresas passaram a ter tratamento diferenciado, simplificado e favorecido (MAIA; ALMEIDA, 2011).

Com a promulgação desta lei, surgiu o Estatuto da Microempresa. O art. 15 dispensava as microempresas de escrituração, obrigando-as somente a manter arquivada a documentação referente aos acontecimentos ocorridos. O objetivo do tratamento diferenciado era o incentivo as microempresas e isso se evidencia com a Constituição Federal de 1988, em seu art. 179: 
a União, os Estados, o Distrito Federal, e os Municípios dispensarão às Microempresas e às Empresas de Pequeno Porte assim definidas em lei, tratamento jurídico diferenciado, viando a incentivá-las pela simplificação de suas obrigações administrativas, tributárias e creditícias, ou pela eliminação ou redução destas por meio da lei.

Portanto, fica claro na Constituição Federal, o tratamento diferenciado referente a microempresas. Quanto à Lei $n^{\circ} 7.256 / 84$, teve dispositivos alterados e revogados durante a sua vigência, especialmente pelas leis $n^{\circ} 8.864 / 94$ e $n^{\circ} 9.317 / 96$.

A Lei $n^{\circ} 8.864$ de 28 de março de 1994 não causou grande impacto, mas inovou com a elevação da receita bruta anual da microempresa, e apresentou a empresa de pequeno porte, já prevista na Constituição Federal (MELCHOR, 1999).

Em 1996 foi sancionada a Lei 9.317, com a denominação de Lei do Simples. Para Melchor (1999), "sem dúvida alguma, esta foi uma das maiores conquistas das micro e pequenas empresas brasileiras".

Em 5 de outubro de 1999 foi aprovada a Lei n $^{\circ}$ 9.841, instituindo o Estatuto da Microempresa e da Empresa de Pequeno Porte, expondo o tratamento jurídico, diferenciado, simplificado e favorecido previsto nos arts. 170 e 179 da Constituição Federal. Com o novo estatuto, foram revogadas as Leis $\mathrm{n}^{\mathrm{o}} 7.256 / 84$ e $^{\mathrm{o}}$ 8.864/94, integrando a Lei do Simples, embora a Lei do Simples esteja também em vigor, pois não fora revogada.

Em 14 de dezembro de 2006 foi aprovada a Lei Complementar $n^{\circ} 123$, atualizada com a LC $n^{\circ} 128 / 2007$. Esta lei institui o Estatuto Nacional da Microempresa e da Empresa de Pequeno Porte; alterando dispositivos das Leis $\mathrm{n}^{\circ} 8.212$ e $\mathrm{n}^{\circ}$ 8.213, de 1991, Consolidação das Leis do Trabalho, da Lei $n^{\circ} 10.189$ de 2001, Lei Complementar $n^{\circ} 63$ de 1990 e revoga a lei ${ }^{\circ} 9.317$ de 1996, denominada Lei do Simples, e lei n ${ }^{\circ} 9.841$ de 1999.

$\mathrm{O}$ art. 1 da lei $\mathrm{n}^{\mathrm{o}}$ 123/2006, estabelece normas gerais referente ao tratamento as MPEs diferenciado e favorecido - no âmbito dos Poderes da União, dos Estados, do Distrito Federal e dos Municípios.

De acordo com o art. 26, da Lei Complementar 123 de 2006, § 2º as microempresas e empresas de pequeno porte deverão manter o livro-caixa onde será escriturada a movimentação financeira e bancária. $\mathrm{O} \S 4^{\circ}$ afirma que as empresas referidas no $\S 2^{\circ}$ ficam sujeitas a outras obrigações acessórias a serem estabelecidas pelo Comitê Gestor.

Conforme art. 27 "As microempresas e empresas de pequeno porte optantes pelo Simples Nacional poderão, opcionalmente, adotar contabilidade simplificada para os registros e controles das operações realizadas, conforme regulamentação do Comitê Gestor". Portanto, as microempresas podem escolher entre a contabilidade simplificada ou não, conforme este artigo.

Existem vários critérios para classificar as empresas no Brasil, como, por exemplo, em relação ao porte, critério qualitativos, quantitativos ou a conjugação dos dois. Uma definição se encontra na Lei Geral das Micro e Pequenas Empresas, lei $n^{\circ} 123 / 2006$, que utiliza a receita bruta para enquadramento de fins tributários. Segundo lei no 123/2006:

Para os efeitos desta Lei Complementar, consideram-se microempresas ou empresas de pequeno porte a sociedade empresária, a sociedade simples e o empresário a que se refere o art. 966 da Lei no 10.406, de 10 de janeiro de 2002, devidamente registrados no Registro de Empresas Mercantis ou no Registro Civil de Pessoas Jurídicas, conforme o caso, desde que: I - no caso das microempresas, o empresário, a pessoa jurídica, ou a ela equiparada, aufira, em cada ano-calendário, receita bruta igual ou inferior a $\mathrm{R} \$$ 240.000,00 (duzentos e quarenta mil reais); 
II - no caso das empresas de pequeno porte, o empresário, a pessoa jurídica, ou a ela equiparada, aufira, em cada ano-calendário, receita bruta superior a $\mathrm{R} \$$ $240.000,00$ (duzentos e quarenta mil reais) e igual ou inferior a $\mathrm{R} \$ 2.400 .000,00$ (dois milhões e quatrocentos mil reais).

Haverá mudanças no supersimples para 2012, segundo Oliveira (2011), o projeto ainda precisa ser votado pelo Congresso. Ainda segundo Oliveira (2011) "Entre as principais mudanças está o aumento de $50 \%$ do teto de faturamento para as micro e pequenas empresas se enquadrarem no Supersimples". As novas regras também elevam o faturamento anual máximo das pequenas empresas de $\mathrm{R} \$ 2,4$ milhões para $\mathrm{R} \$ 3,6$ milhões; e para as microempresas de $\mathrm{R} \$ 240$ mil para $\mathrm{R} \$ 360$ mil.

O BNDES conceitua as empresas por portes através do valor da receita anual em reais. É considerada uma microempresa a empresa que aufere receita anual de 1,2 milhão; a pequena empresa com receita anual de 1,2 milhão a 10,5 milhões; a média empresa com 10,5 milhões a 60 milhões; e grande empresa acima de 60 milhões. (MORAIS, 2011)

O CFC, na NBC TG 1000, seção 1, define que pequenas e médias empresas são empresas que não possuem obrigação pública de prestação de contas e elaboram demonstrações contábeis para fins gerais de usuários externos.

\subsection{Normas Brasileiras de Contabilidade para PME - Aspectos Históricos}

Em 2007, o CFC, preocupado com o disposto no art. 27 da Lei Complementar $n^{\circ}$ 123/06, constituiu uma comissão técnica para tratar do tema da lei.

Conforme o CRC/SC (2008) preceitua a respeito da escritura "Escrituração Contábil Simplificada para micro e pequena empresa", é consenso entre os profissionais da contabilidade que apenas o CFC edite as normas referentes a escrituração contábil. Assim, em julho de 2007, a comissão técnica apresentou ao Comitê Gestor do Simples Nacional, uma proposta de NBC (2008, p.11) "facultando para as MEs e EPPs o regime de escrituração contábil simplificada e, não, de contabilidade simplificada, conforme redação equivocada do art. 27 da LC n ${ }^{\circ}$ 123/06. A presente publicação trata de escrituração simplificada, portanto inexiste contabilidade simplificada".

Após este trâmite, a proposta foi posta em audiência publica e, em dezembro de 2007, foi editada a Resolução CFC $\mathrm{n}^{\circ} 1.115 / 07$, aprovando a NBC $\mathrm{T} 19.13$, que fala sobre a Escrituração Simplificada para MPEs.

Portanto, ainda conforme a introdução CRC/SC (2008, p.12) "a Escrituração contábil simplificada, no mínimo obrigatória para as empresas contempladas pelas disposições da LC $\mathrm{n}^{\circ} 123 / 06$, alterada pela LC $\mathrm{n}^{\circ} 127 / 07$, está contextualizada pela NBC T 19.13, tratada na Resolução CFC n' 1.115/07'”.

A Resolução CFC no 1.255 aprovou em 10 de dezembro de 2009 a NBC T 19.41 Contabilidade para Pequenas e Médias Empresas - que entrou em vigor nos exercícios iniciados em $1^{\circ}$ de janeiro de 2010.

A Resolução CFC nº 1.329 de 2011 alterou a sigla e a numeração da NBC 19.41 para NBC TG 1000.

Segundo o CFC (2010, p. 9), as normas, interpretações e comunicados técnicos são emitidos:

[...] de forma convergente com as Normas Internacionais de Contabilidade emitidas pelo IASB e promoção do uso dessas normas em demonstrações contábeis para fins gerais no Brasil e outros relatórios financeiros. Ostros relatórios financeiros compreendem informações fornecidas fora das demonstrações contábeis que 
auxiliam na interpretação do conjunto completo de demonstrações contábeis ou melhoram a capacidade do usuário de tomar decisões econômicas eficientes.

As normas, interpretações e comunicados técnicos emitidos pelo CFC, são elaborados para a aplicação de demonstrações contábeis para fins gerais e outros relatórios financeiros destinados a empresas que tenham fins lucrativos. As demonstrações contábeis para fins gerais devem abranger usuários externos e o público em geral que tenha algum tipo de interesse nestas demonstrações. Segundo CFC (2010, p. 9) "o objetivo das demonstrações contábeis é oferecer informações sobre a posição financeira ( balanço patrimonial), o desempenho (demonstração do resultado) e fluxos de caixa da entidade, que seja útil aos usuários para a tomada de decisões econômicas."

Vimos assim, a partir da NBC T 19.41, atual NBC TG 1000, a preocupação do CFC em emitir normas que sirvam para a tomada de decisões. Segundo HOSS et al. (2006, p. 41) o objetivo da contabilidade é "gerar e fornecer informações contábeis a respeito dos patrimônios das entidades de forma útil e relevante para que seus usuários possam tomar decisões". Ressaltamos assim a importância da contabilidade em fornecer informações através dos relatórios contábeis que permitem a gerência da empresa e o processo de tomada de decisões. Assim, o CFC emitiu em separado a NBC TG 1000, para serem aplicadas nas empresas de pequeno e médio porte as demonstrações contábeis para fins gerais. São empresas compostas por capital fechado e sociedades que não necessitem prestação pública de contas.

\section{METODOLOGIA}

Esta pesquisa tem por objetivo caracterizar a importância da informação contábil para a gestão das Pequenas e Médias Empresas e evidenciar as contribuições da NBC TG 1000 para essas empresas, em relação à NBC T 19.13.

Para destacar as alterações nos procedimentos legais e normativos das normas contábeis, foi utilizada a pesquisa bibliográfica, onde se teve por objetivo apresentar os procedimentos vigentes na gestão das micro e pequenas empresas. Segundo Marconi e Lakatos (2009), a pesquisa bibliográfica possibilita o contato direto do pesquisador e sobre o que foi escrito sobre determinado assunto. Nesta acepção, a pesquisa bibliográfica instrumentalizou a revisão da legislação e das normas procedimentais utilizadas na gestão das micro e pequenas empresas, sobretudo nas NBC T 19.13 e NBC TG 1000.

A abordagem deste estudo foi realizada de forma qualitativa, de acordo com Richardson (1999, p. 80):

\footnotetext{
Os estudos que empregam uma metodologia qualitativa podem descrever a complexidade de determinado problema, analisar a interação de certas variáveis, compreender e classificar processos dinâmicos vividos por grupos sociais, contribuir no processo de mudança de determinado grupo e possibilitar, em maior nível de profundidade, o entendimento das particularidades do comportamento dos indivíduos.
}

A abordagem qualitativa permitiu uma leitura, análise e interpretação das alterações nas normas brasileiras de contabilidade que orientam procedimentos das pequenas e micro empresas. Foi possível identificar contribuições no processo de gestão ao mesmo tempo em que se evidencia um processo de mudança na mentalidade empresarial. No conjunto, tais mudanças corroboram o desenvolvimento do pensamento contábil bem como as contribuições da ciência no contexto social das ciências aplicadas e seu objeto de análise. A análise 
qualitativa tem assim sua relevância ao apresentar os aspectos da gestão patrimonial das micro e pequenas empresas e suas relações com o universo exequível em que se insere.

\section{ANÁLISE DAS NORMAS NBC T 19.13 E NBC TG 1000}

A Resolução CFC n ${ }^{\circ} 1.115$, de 14 de dezembro de 2007 aprova a NBC T 19.13, que trata de critérios e procedimentos específicos para a escrituração contábil simplificada de microempresa e empresa de pequeno porte, conforme a legislação vigente.

A permissão legal de optar por escrituração contábil simplificada não desobriga de manter escrituração contábil uniforme.

Quanto às demonstrações contábeis, conforme a NBC T 19.13 (2010, p. 643), a micro empresa e a empresa de pequeno porte devem elaborar o Balanço Patrimonial e a Demonstração do Resultado no final de cada exercício social e estas demonstrações devem ser transcritas no Livro Diário. A norma faculta a elaboração da Demonstração de Lucros ou Prejuízos Acumulados, das Demonstrações das Mutações do Patrimônio Líquido, da Demonstração das Origens e Aplicações de Recursos e das Notas Explicativas.

O Plano de Contas também poderá ser simplificado. No entanto, deve ser elaborado conforme CFC na NBC T 19.13 (2010, p. 643):

\footnotetext{
levando em consideração as especificidades, porte e natureza das atividades e operações a serem desenvolvidas pela microempresa e empresa de pequeno porte, bem como em conformidade com suas necessidades de controle de informações no que se refere aos aspectos fiscais e gerenciais.
}

Com a NBC TG 1000, podem-se ver grandes mudanças na obrigatoriedade de algumas demonstrações e relatórios, gerando um número maior de informações que poderão auxiliar na gerência da microempresa.

De acordo com a NBC TG 1000 (2010, p. 13):

o objetivo das demonstrações contábeis de pequenas e médias empresas é oferecer
informação sobre a posição financeira (balanço patrimonial), o desempenho
(resultado e resultado abrangente) e fluxos de caixa da entidade, que é útil para a
tomada de decisão por vasta gama de usuários que não está em posição de exigir
relatórios feito sob medida para atender suas necessidades particulares de
informação.

Pode-se ver que a norma se preocupa com demonstrações que auxiliem a gestão da empresa. Conforme esta norma, as demonstrações contábeis exigidas são: Balanço Patrimonial, Demonstração do Resultado do período de divulgação, Demonstração do Resultado Abrangente do período de divulgação, Demonstração das Mutações do Patrimônio Líquido, Demonstração do Fluxo de Caixa e Notas Explicativas.

Enquanto a NBC T 19.13 pedia um número pequeno de demonstrações, a NBC TG 1000 exigia muitas outras. Um exemplo a comentar são as notas explicativas, que não eram exigidas e com as alterações nas normas passaram a ser obrigatórias. Salienta-se que nas notas explicativas deve-se divulgar o endereço do escritório central ou principal local de operação, a forma legal da entidade e a natureza das operações da entidade, bem como de suas principais atividades. 
A NBC TG 1000 não exige a apresentação de informações por segmentos, lucro por ação, nem mesmo demonstrações contábeis intermediárias para empresas de pequeno e médio porte.

Verifica-se no Quadro 01, as diferenças entre a NBC T 19.13 e a NBC TG 1000.

\begin{tabular}{|l|l|l|}
\hline & NBC T 19.13 & NBC TG 1000 \\
\hline Legislação & Lei Geral & Lei Geral \\
\hline Contabilidade & Simplificada & Completa \\
\hline Demonstrações Contábeis & $\begin{array}{l}\text { Balanço Patrimonial e e } \\
\text { Demonstração de Resultado }\end{array}$ & $\begin{array}{l}\text { Balanço Patrimonial e } \\
\text { Demonstração de Resultado, } \\
\text { Demonstração de Lucros ou } \\
\text { Prejuízos Acumulados, das } \\
\text { Demonstrações das Mutações } \\
\text { do Patrimônio Líquido, da } \\
\text { Demonstração das Origens e } \\
\text { Aplicações de Recursos e das } \\
\text { Notas Explicativas }\end{array}$ \\
\hline $\begin{array}{l}\text { Objetivo das } \\
\text { Demonstrações Contábeis }\end{array}$ & Fiscal & Fiscal e Gerencial \\
\hline Plano de Contas & Simplificado & Detalhado \\
\hline
\end{tabular}

Quadro 01: Comparativo da NBC T 19.13 e NBC TG 1000

Fonte: NBC T 19.13 (2007) e NBC TG 1000 (2011)

Pode-se perceber no quadro 01 algumas das diferenças entre a NBC T 19.13 e a NBC TG 1000. Ambas são regidas pela mesma legislação, mas a NBC T 19.13 permite contabilidade simplificada somente com Balanço Patrimonial e Demonstração de Resultado, com objetivo fiscal e Plano de Contas Simplificado. Enquanto a NBT TG 1000 exige contabilidade completa, visando também a gerência da empresa com todos os demonstrativos necessários para a tomada de decisão, com Plano de Contas completo.

\subsection{A importância das informações contábeis para a gestão pequenas e médias empresas}

As informações contábeis auxiliam na gestão e tomada de decisão, tanto em grandes quanto em pequenas empresas, pois as pequenas empresas também precisam de um sistema de informações. Segundo Yamamoto e Salotti (2006, p. 5):

(...) a informação contábil pode ser considerada como aquela que altera o estado da arte do conhecimento de seu usuário em relação à empresa e, a partir de interpretações, a utiliza na solução de problemas, sendo a natureza da informação contábil, entre outras, econômico-financeira, física e de produtividade.

Assim, a informação contábil auxiliará o usuário com interpretações e soluções de problemas em relação à empresa.

O sistema de informações apoiando a gestão auxiliará os sócios, empreendedores e administradores com análises e decisões que deverão ser tomadas respectivas à empresa e suas atividades operacionais relacionadas com a gestão e estratégia organizacional. O sistema de informação realizado de forma a ser estruturado e informatizado é importante também para 
as pequenas empresas. Verifica-se hoje um processo de mudança global e as pequenas empresas que não se adaptarem a este avanço tecnológico e de organização das informações, estarão sujeitas ao desgaste e morte. (SOUZA, 2011)

Conforme Yamamoto e Salotti (2006, p. 7) "a informação contábil relaciona-se aos objetivos da contabilidade de mensurar o conjunto de eventos econômicos e comunicar os resultados das entidades às partes interessadas, constituindo um de seus produtos". Sendo assim, verifica-se que mensurar eventos econômicos e comunicar os resultados é um dos objetivos da contabilidade. Sabe-se que a contabilidade deve ser feita também em micro e pequenas empresas, portanto, a informação contábil será também importante para a gestão dessas empresas e deve ser realizada de forma estruturada e organizada.

Em uma pesquisa realizada pelo SEBRAE, entre os anos de 2003 a 2005, sobre "os fatores condicionantes e taxas de sobrevivência em mortalidade das micro e pequenas empresas no Brasil", 68\% dos empresários das empresas extintas afirmaram que a principal razão para a empresa ter sido fechada está centrada em falhas gerenciais. Por isso a necessidade de se ter a contabilidade voltada para atender e gerar informações também para a gerência da empresa. Conforme Padoveze (2010, p. 51):

\footnotetext{
Caso os conceitos de utilidade e necessidade da informação contábil não estejam imediatamente presentes no ambiente da cúpula administrativa da entidade, é tarefa do contador fazer nascer e crescer essa mentalidade gerencial. Para isso, é necessário apenas o conhecimento profundo da Ciência Contábil e de seu papel informativogerencial.
}

Indubitavelmente, um passo importante foram as mudanças ocorridas nas Normas Brasileiras de Contabilidade, quando se refere a micro empresas e empresas de médio porte, pois agora a contabilidade gerará um número maior de informações do que quando utilizava uma contabilidade simplificada; informações estas que auxiliaram na gestão e tomada de decisão destas empresas.

\section{CONSIDERAÇÕES FINAIS}

Com a análise comparativa entre as normas, observou-se que a NBC T 19.13 permitia a contabilidade simplificada; não eram muitos os relatórios contábeis exigidos e até mesmo o plano de contas era simplificado. Já a NBC TG 1000 exige contabilidade completa, isto é, os relatórios contábeis exigidos são vários, todos usados obrigatoriamente por uma sociedade de capital aberto e que passaram a ser exigidos também para as pequenas e médias empresas, visando a qualidade das decisões com um número maior de informações e controle do patrimônio. Além de adequar-se as normas internacionais.

Para uma melhor gestão é necessário a contabilidade completa, que fornece maior número de informações para a tomada de decisão, já que muitos são os dados que devem ser observados e informações que devem ser coletadas para cálculos de uma série de áreas importantes que envolvem uma empresa, como custos e preços de venda. A pesquisa realizada pelo SEBRAE mostra que um dos maiores motivos para a mortalidade das empresas é de questões gerenciais.

Portanto, como a NBC TG 1000 fornece uma gama maior de dados, com demonstrativos necessários para a gestão, fica evidente que as pequenas e médias empresas seguindo a NBC TG 1000 terão mais subsídio para gerenciar a empresa. Ainda não será uma contabilidade 
gerencial perfeita, pois essa exigiria muitos outros relatórios internos, mas já seria uma forma de melhor controlar o patrimônio, com informações relevantes.

Foi caracterizada neste estudo a importância da informação contábil para a gestão de pequenas e médias empresas, pois são problemas gerenciais um dos maiores motivos para a mortalidade destas empresas que possuem uma importância relevante para a economia do país.

Os benefícios alcançados pelas pequenas e médias empresas com as mudanças nas Normas Brasileiras de Contabilidade são um número maior de informações fornecidas pela contabilidade, que dão maior subsídio para a tomada de decisão.

Como sugestões para trabalhos futuros têm-se a verificação na prática de que maneira essas mudanças estão sendo feitas dentro dos escritórios contábeis e das pequenas e médias empresas, e quais as dificuldades enfrentadas para seguir a nova norma estabelecida.

\section{REFERÊNCIAS}

BONFANTI, Cristiane. Micro e pequenas empresas aproveitam o bom momento da economia. Correio Braziliense. Disponível em:

$<\mathrm{http}$ ://www.correiobraziliense.com.br/app/noticia/economia/2011/01/24/internas_economia, 233865/micro-e-pequenas-empresas-aproveitam-o-bom-momento-da-economia.shtml>. Acesso em: 20 maio 2011.

BRASIL. Constituição da República Federativa: Texto constitucional promulgado em 5 de outubro de 1988, com as alterações adotadas pelas emendas Constitucionais no $1 / 92$ a 44/2004 e pelas Emendas Constitucionais de Revisão nº 1 a 6/94. Brasília: Senado Federal, Subsecretaria de Edições Técnicas, 2004.

CONSELHO FEDERAL DE CONTABILIDADE. Contabilidade para pequenas e médias empresas: Normas Brasileiras de Contabilidade NBC T 19.41. Brasília: CFC, 2010.

CONSELHO REGIONAL DE CONTABILIDADE DE SANTA CATARINA. Escrituração contábil para micro e pequena empresa.Florianópolis: CRCSC, 2008.

COUTINHO, Luciano. O cenário econômico e as MPE. Banco Nacional do Desenvolvimento. Disponível em:

$<$ http://www.bndes.gov.br/SiteBNDES/export/sites/default/bndes_pt/Galerias/Arquivos/empr esa/download/apresentacoes/Coutinho_CenarioEconomicoeMPE_set10.pdf>. Acesso em: 25 set. 2011.

FÓRUM PERMANENTE DAS MICROEMPRESAS E EMPRESAS DE PEQUENO PORTE. Desenvolvimento Tecnológico e Inovação nas Microempresas e Empresas de Pequeno Porte: Fatores de Influência. Disponível em: < http://www.mdic.gov.br/arquivos/dwnl_1202923119.pdf> Acesso em: 09/10/2011

HENRIQUE, Marco Antônio. A importância da contabilidade gerencial para micro e pequena empresa. 2008. 79 f. Monografia (Especialização) - Universidade de Taubaté, 
Taubaté, 2008. Disponível em: <http://br.monografias.com/trabalhos-pdf/contabilidadegerencial-micro-pequena-empresa/contabilidade-gerencial-micro-pequena-empresa.pdf $>$. Acesso em: 09 out. 2011.

HOSS, Osni et al. Conhecimento e Aplicação Contábil. Cascavel: Editora DRHS - Osni Hoss, 2006.

INSTITUTO BRASILEIRO DE GEOGRAFIA E ESTATÍSTICA - IBGE. As Micro e pequenas empresas comerciais e de serviços no Brasil: 2001. IBGE, Coordenação de Serviços e Comércios: Rio de Janeiro, 2003.

MAIA, Henrique Manoel Ribeiro; ALMEIDA, Vamberto Torres de. A Lei Geral da Micro e Pequenas Empresas: Uma síntese das principais Medidas aprovadas na Lei Complementar no 123/2006. Disponível em:

$<$ http://www.biblioteca.sebrae.com.br/bds/BDS.nsf/BC1509BCDBF411CA83257442006FFC 71/\$File/NT00037926.pdf>. Acesso em: 20 jun. 2011.

MARCONI, Maria de Andrade; LAKATOS, Eva Maria. Fundamentos de metodologia científica. São Paulo: Atlas, 2009.

MELCHOR, Paulo. Leis da Microempresa e Empresa de Pequeno Porte e o novo estatuto. (Lei 9841/99). Jus Navigandi, Teresina, ano 4, n. 37, 1 dez. 1999. Disponível em: $<$ http://jus.uol.com.br/revista/texto/751>. Acesso em: 16 jun. 2011.

MORAIS, José Mauro de. PROGRAMAS ESPECIAIS DE CRÉDITO PARA MICRO, PEQUENAS E MÉDIAS EMPRESAS: BNDES, PROGER E FUNDOS CONSTITUCIONAIS DE FINANCIAMENTO. Disponível em: $<$ http://www.ipea.gov.br/sites/000/2/livros/inovacaotecnologica/capitulo10.pdf>. Acesso em: 10 out. 2011.

OLIVEIRA, Ana Carolina. Novas regras para o Supersimples só entram em vigor em 2012. Disponível em: <http://www1.folha.uol.com.br/mercado/958484-novas-regras-para-osupersimples-so-entram-em-vigor-em-2012.shtml>. Acesso em: 24 set. 2011

PADOVEZE, Clóvis Luís. Contabilidade gerencial: um enfoque em sistema de informação contábil. 7. ed. São Paulo: Atlas, 2010.

RICHARDSON, Roberto Jarry. Pesquisa social: métodos e técnicas. 2 ed. São Paulo: Atlas, 1999.

SEBRAE. Regulamentação da lei geral nos estados. Disponível em:

$<$ http://www.sebrae.com.br/customizado/lei-geral/regulamentacao-da-lei-geral-nosestados/estatisticas-de-implantacao-da-lei-geral/numeros-de-municiadpios-por-estado $>$. Acesso em: 18 maio 2011. 
SEBRAE. Lei Geral. Disponível em: <http://www.sebrae.com.br/customizado/lei-geral/leigeral/legislacao/lei-geral-na-integra/lei-geral-na-integra-atualizada-ate-06-10-2009>. Acesso em: 18 maio 2011.

SILVA, A.C.R da; AMORIM, D.S de; SILVA, R.B. da. Gestão estratégica da informação contábil: Um enfoque no Gerenciamento de Micro e Pequenas Empresas. Disponível em: $<$ http://www.acim2011.org/papers/PT/Estrategia\%20e\%20Organizacao/Gestao\%20Estrategic a\%20da\%20Informacao\%20Contabil\%20-

$\% 20 \mathrm{Um} \% 20 \mathrm{Enfoque} \% 20 \mathrm{no} \% 20 \mathrm{Gerenciamento} \% 20 \mathrm{de} \% 20 \mathrm{Micro} \% 20 \mathrm{e} \% 20 \mathrm{Pequenas} \% 20 \mathrm{Em}$ presas.pdf> Acesso em: 09 de outubro de 2011.

SOUZA, Luiz Carlos de. Controladoria aplicada aos pequenos negócios. Curitiba: Juruá, 2011. $146 \mathrm{p}$.

VILGA, V. F; FARAH, O. E; GIULIANI. Pequenas empresas: a má administração e a alta taxa de mortalidade. Disponível em:

$<$ http://www.dad.uem.br/adm/graduacao/download/2762-39.pdf>. Acesso em: 09 de outubro de 2011.

YAMAMOTO, Marina M.; SALOTTI, Bruno M. Informação Contábil: Estudos sobre a sua divulgação no mercado de capitais. São Paulo: Atlas, 2006. 